\title{
How Strategic Human Resource Planning Influence Performance of Agricultural Research Institutes in Kenya
}

\author{
Yusuf W. Musi ${ }^{1}$, E. Mukulu ${ }^{2} \&$ M. Oloko ${ }^{1}$ \\ ${ }^{1}$ Jomo Kenyatta University of Science and Technology, Nairobi, Kenya \\ ${ }^{2}$ Kenya Agricultural and Livestock Research Organisation, Kenya \\ Correspondence: Yusuf Wanjala Musi, Jomo Kenyatta University of Science and Technology, P. O. Box \\ 62000-00200 Nairobi, Kenya. E-mail: musiwanjala@yahoo.com
}

\author{
Received: November 19, 2018 Accepted: December 20, 2018 Online Published: January 24, 2019 \\ doi:10.5539/jms.v9n1p48 URL: https://doi.org/10.5539/jms.v9n1p48
}

\begin{abstract}
Strategic planning is a tool that determines the destiny of an individual, institution or organization. Globally, competition defines strategies encompassed by institutions due to industrial economy that had been experienced to pass toward knowledge resource. Efficiency is achieved by successful utilization of resources. Organisations seek a more competitive edge at all costs and turn to more innovations in information technology. Effective measures provide decision makers with feedback on the effect of deliberate actions and influence critical decisions such as resources allocations, as well as appropriate action as may be necessary. This study was carried out in Kenya Agricultural and Livestock Research Organisation (KALRO) to determine how strategic human resource influence the performance of agricultural research organisations. It was anchored on the theory of transformational leadership theory. Information on whether research organisations apply strategic human resource planning in management was scarce. This was partly due to the little attention that was drawn on quality of services offered and feedback. Although there had been previous international studies in this field, no similar work had been conducted in agricultural-based research organisations in Kenya. This study therefore sought to establish whether strategic human resource planning could influence performance in agricultural research organizations. Survey research design was used. The study comprised of four agricultural research institutes. The Institutes had a total of 2922 employees in 2016. A structured questionnaire was administered to collect primary data. A pilot test was conducted on $10 \%$ of the total respondents to test reliability and validity. Reliability of the instrument was determined by use of Cronbach's alpha coefficient. The Pearson's product moment correlation was used to establish test for linearity using Statistical Package for Social Sciences, (SPSS 2018), while Analysis of Variance was used to test hypothesis. Results showed that strategic human resource management contributes to increased agricultural research performance in KALRO institutes. It is recommended that the findings of this study be embraced by other agricultural research institutions in Kenya.
\end{abstract}

Keywords: strategic human resource planning, organisations' performance, agricultural research

\section{Introduction}

Globally, competition defines institutions strategies as a result of industrial economy. Strategic planning is a tool that determines the destiny of an institution. An institution's efficiency is achieved by successful allocation and utilization of resources. Innovations through dynamic leadership and information technology had been adopted by institutions to be more competitive. Effective measures assist decision makers and top managers with feedback on the effect of planned actions that affect critical issues such as allocation of resources and whether to maintain or revise existing strategies.

\subsection{Study Overview}

Formal strategic planning began in the 1950s in the United States of America championed by Peter Drucker. According to Kenneth (2006), strategy content was a subset of generally accepted management function in public organisations. Regionally, Fubara (1986) did a survey in Nigeria and observed that companies that engaged in formal planning experienced growth in profits as opposed to those that did not. Also, Arasa and K'Obonyo (2012) noted that within the African context, firms that practiced strategic planning recorded higher performance than those without strategic planners. 
Kenya was the leading country in East and Central Africa in terms of research institutes with a growing demand for more industrial and academic output justifying the large numbers (GoK, 2007). The main categories of research institutions included agricultural crops, livestock, forestry, fisheries, academic and socioeconomics. The study focused on four institutions (Kenya Agricultural Research Institute [KARI], Coffee Research Foundation [CRF], Tea Research Foundation [TRF] and the Kenya Sugar Research Foundation [KESREF] that were merged to form the Kenya Agricultural and Livestock Research Organization's (KALRO). Key concepts in early organisational theory were rationality, effectiveness, efficiency and control.

\subsection{Statement of the Problem}

Ensuring the right people with the right skills, knowledge, attributes and atitute has lacked in KALRO for long.

This study was carried out to determine how strategic human resource planning influence agricultural research organisations' performance in Kenya. It was anchored on whether agricultural institutions of Kenya had adopted strategic human resource planning in management of research organisations. For a long time, employees in agricultural institutions had been demoralised, lost hope, demotivated and stagnated in career.

Information on whether research institutes use strategic human resource was scarce. This was partly due to little attention put on evaluation and reward tagged on output and effort. Though there were international studies in this area of study, very limited studies had been conducted in agricultural-based research in Kenya on strategic human resource planning and performance. This study, therefore, sought to establish whether strategic human resource planning influence performance in agricultural research institutions of Kenya.

\section{The Study Theory}

\subsection{Transformational Leadership Theory}

Transformational leadership theory focuses on the assumption that leaders influence followers through persuasion to teams to undertake intent (Purvanova, Bono, \& Dzieczynski, 2006). This is important for effective succession planning and management at different levels in an arrangement. According Burns (1978), transformative leadership aims to uplift an entity to higher levels of motivation. It encompasses the employee being developed, along with the arrangement of their senior to engage them in the process. Leaders need to be able to motivate and engage their workers in order to increase productivity. Those being mentored for leadership should possess and yearn to create meaningful work for themselves and others.

Transformational leadership theory fits into the succession planning and management equation of strategic human resource planning for enhancing orgainsational performance. According to Purvanova, Bono and Dzieweczynski, (2006), this theory explains one of the fundamental ways in which leaders influence followers. This refers to creating meaningful work transformative leadership though use of charismatic and inspirational individualised consideration to followers through attending to followers' individual needs for individual development (Bass, 1985). Transformational leadership approach results in more engaged, devoted and less self- individualised employee as well as in workers who perform beyond the level of expectations (Purvanova, Bono, \& Dzieweczynski, 2006). In a nutshell, transformational leadership is about achieving results beyond expectations in a harmonious undertaking. In succession planning and management, this theory could be a key component for success in organisation performance. Having transformative leadership with these traits involve planning process that could enable greater engagement in the process and success of the undertaking over time.

In developing and maintaining successful succession planning and management process in agricultural research in Kenya, there needs to be an inculcation of this transformation theory. This could be through analysis of the influence of the theory for future of agricultural research organisations and her management structure. In cases where the undertaking is implemented without employing the underlying theory, there could be a strong likelihood of disfunctionality. This could be due to not completely understanding the nature of the individuals involved and their work environment, their motivations and external pressures that could affect how succession planning and management approach being executed.

This finding was an important one in agricultural research organisations in Kenya since the sector was an even dynamic industry and this meant that the skills needed to be successful were prone to high turnover. Organisations need to be sufficiently strategic to anticipate the skills and competencies necessary to take their organisations through future five to ten years and beyond. They also need to understand the attitude and culture of their human resource and the operational industry in general. Past were the days when people stayed in single employment for their entire career. In the current millennial age, employees now see that they may need short term employment around organizations in order to achieve prestige and success. Byham, Smith, and Pease (2002) propounded the need to have talent pools rather than look at one individual for each position available. This theory was important 
to this study to the extent that research set up entails continued, creativity and innovation that deserve strategic approaches to decision making.

\subsection{Objective}

The objective of the study was to assess the influence of strategic human resource planning on the performance of agricultural research institutions' performance in Kenya.

The study was guided by the following hypothesis:

$\mathrm{H}_{1}$ : Strategic human resource planning had no significant influence on agricultural research organizations' performance in Kenya.

\section{Research Design}

The descriptive survey followed (state the procedure) and made it possible to interpret data collected. Here, research questions were raised and answered in a descriptive manner. In descriptive research, the events or conditions either already existed or had occurred and the researcher mainly selects the relevant variables for analysis for their relationships (Best \& James, 1993).

\subsection{Target Population}

The population of this study was 2922 and a sample size of 352 employees of the Kenya Agricultural and Livestock Research institutes as per formula propounded by (Yamane, 1967). The population was a larger collection of all subjects from where a sample was drawn and referred to an entire group of individuals, events or objects having common observable characteristics (Mugenda, 2003).

\subsection{Sampling Frame and Sampling}

Sampling was through a process of selecting institutions of KALRO from a population 16 institutions, then randomly administering a questionnaire to the area of interest so that by studying the sample the results could be generalized based on the population of interest. A Sampling frame referred to a list, directory or index of cases from which a sample could be selected (Mugenda, 2003). A sampling frame for the study comprised of all employees from the four institutions, namely: The institutions had 2922 employees as at 2016, of which 352 was randomly sampled.

Table 1. Composition of the cluster samples

\begin{tabular}{llll}
\hline Institution & Category of Staff & Total & Sample Size \\
\hline KALRO-KARI & Top level & 496 & 60 \\
& Middle Level & 998 & 62 \\
& Lower Level & 1014 & 40 \\
CRI & Top level & 55 & 35 \\
& Middle Level & 69 & 30 \\
& Lower Level & 40 & 25 \\
TRI & Top level & 31 & 30 \\
& Middle Level & 50 & 20 \\
& Lower Level & 52 & 10 \\
SRI & Top level & 25 & 20 \\
& Middle Level & 40 & 15 \\
& Lower Level & 52 & 5 \\
Total & & 2922 & 352 \\
\hline
\end{tabular}

\subsection{Validity of Research Instruments}

Validity indicated the degree of accuracy, soundness and effectiveness to which an instrument measured what it was meant to measure (Orodho, 2005). Also, it measured the degree to which results obtained from the analysis of the data represented the phenomena under study (Mugenda, 1999). Validity was determined by the use of face validity and content validity. Face validity tested if the questions appeared to be measuring the intended sections. On the other hand, content validity tested whether all the important aspects of the sections were measured. The researcher determined the validity of the instrument by seeking expert opinion from the supervisors and KALRO research scientist. This was done by first testing the instruments on $10 \%$ questionnaires to the target population and reviewing the findings based on outcome. 


\subsection{Reliability of Research Instruments}

Reliability is a measure of the degree to which a research instrument yields consistent results after repeated trials (Mugenda, 2003). Reliability of the instrument was determined by use of Cronbach's Alpha Coefficient version 21. The variable was found to reflect final research questionnaire that attained the reliability threshold.

\subsection{The Ordinal Logistic Regression Technique}

The response variable-firm performance (liquidity) denoted by $Y$ has three levels measured on a three-point Likert scale as high, moderate and low. Therefore, arranging the three levels of $Y$ in a hierarchical manner gives:

High $>$ moderate $>$ low

Using the ordinal logistic regression technique and assuming a proportional odds model, with the level low taken as the reference category, two ordinal logistic regression models are fitted simultaneously onto the data.

$$
\begin{aligned}
& {\left[\frac{P(Y=\text { low })}{P(Y=\text { moderate, high })}\right]=\exp \left(\hat{\mathrm{a}}_{01}+\hat{\mathrm{a}}_{1} X_{1}+\hat{\mathrm{a}}_{2} X_{2}+\hat{\mathrm{a}}_{3} X_{3}+\ldots+\hat{\mathrm{a}}_{k} X_{k}\right)} \\
& {\left[\frac{P(Y=\text { low, moderate })}{P(Y=\text { high })}\right]=\exp \left(\hat{\mathrm{a}}_{02}+\hat{\mathrm{a}}_{1} X_{1}+\hat{\mathrm{a}}_{2} X_{2}+\hat{\mathrm{a}}_{3} X_{3}+\ldots+\hat{\mathrm{a}}_{k} X_{k}\right)}
\end{aligned}
$$

For the categorical explanatory variables, this statistical technique outputs a measure called the odds ratio, which in simple terms; gives a relative comparison of one categorical value (event occurring) against another value (event not occurring) termed as the reference category.

Therefore, given a categorical explanatory variable $X_{i}$ and the regression co-efficient $\hat{a}_{i}$, the odds ratio denoted by OR.

\section{Results and Discussion}

According to Orodho (2003), response rate was the extent to which the final data sets include all sampled members and was calculated as the number of respondents with whom interviews were completed and divided by the total number of respondents of the entire sample including none respondents. Questionnaires were administered to 352 respondents and 305 respondents returned the duly filled questionnaires. This translated to a response rate of $86.64 \%$. The high response rate was attributed to the fact that questions were semi-structured hence made it easy for the respondents to fill and the researcher being in constant contact with them. This response rate was satisfactory to draw conclusion from the study and was therefore sufficiently representative. This was based on Mugenda and Mugenda (1999), in which they asserted that a response rate of 50\% was adequate for analysis and reporting; $60 \%$ was generally good while more than $70 \%$ was excellent. This was also the same position taken by Babbie (2010), who asserted that a response rate of above $70 \%$ was deemed to be very good. The high response rate of $162(46 \%)$ by KARI, 90 (25\%) by CRI, $60(17.04 \%)$ by SRI and $40(11.36 \%)$ by TRI was an indication that the results of the study were reliable and adequate.

\subsection{Reduction of SHRP Variables Factors}

Strategic human resource planning enables research institutes to have the desired levels of staff necessary to achieve their objectives. All the nine independent variable items in the strategic human resource planning were confirmed valid due to their factor loading values (Table 2).

Table 2. Showing SHRP resource factors

\begin{tabular}{lllll}
\hline Rotated Component Matrix $^{\mathrm{a}}$ & \multicolumn{3}{c}{} \\
\cline { 2 - 5 } & 1 & 2 & 3 & Component \\
\hline HRP alignment & 0.823 & 0.055 & 0.053 & -0.171 \\
HRP importance & 0.818 & 0.124 & 0.020 & 0.087 \\
HR Demand forecast & 0.009 & 0.641 & 0.053 & -0.109 \\
HR Supply forecast & 0.084 & 0.489 & -0.013 & 0.010 \\
HR resource requirement & 0.413 & 0.474 & 0.049 & 0.340 \\
Manpower Planning Model & -0.337 & 0.390 & 0.323 & -0.174 \\
No of Employees & -0.268 & 0.161 & -0.696 & -0.111 \\
Primary Industry & -0.100 & 0.155 & 0.692 & -0.012 \\
HRP improve recession & -0.159 & -0.258 & 0.172 & 0.737 \\
HRP system rating & 0.197 & 0.460 & -0.242 & 0.563 \\
\hline
\end{tabular}


Extraction method that was used was principal component analysis. Rotation method that was used was Varimax with Kaiser Normalization. Rotation converged in 9 items. Table 2 shows outcomes from strategic human resource planning factors that were asked to the respondents. It was identified that the variables had similarities; hence it could be convenient for the research to cluster the variables measuring similar traits as propounded by Field (2009). Rotation convergence of the 10 items was as shown in Table 3.

Table 3. The SHRP factors rotated component matrix

\begin{tabular}{|c|c|c|c|c|}
\hline \multicolumn{5}{|l|}{ Rotated Component Matrix $^{\mathrm{a}}$} \\
\hline & \multicolumn{4}{|c|}{ Component } \\
\hline & 1 & 2 & 3 & 4 \\
\hline HRP alignment & 0.823 & & & \\
\hline HRP importance & 0.818 & & & \\
\hline HR Demand forecast & & 0.641 & & \\
\hline HR Supply forecast & & & & \\
\hline HR resource requirement & & & & \\
\hline No of Employees & & & -0.696 & \\
\hline Team Building & & & 0.692 & \\
\hline HRP improve recession & & & & 0.737 \\
\hline HOD Participation in Sourcing & & & & 0.563 \\
\hline
\end{tabular}

Extraction method that was used was principal component analysis. Rotation method that was used was Varimax with Kaiser Normalization. Rotation converged in 10 iterations. Table 3 demonstrates the principal component analysis (PCA) of human resource factors rotated matrix. The matrix was used for clustering in order to reduce the variables that had similar traits or attributes. PCA is a statistical technique for identifying groups or clusters of variables by reducing large data-set with several variables to manageable sizes while retaining much of original information as much as possible. The data reduction was achieved by identifying the variables which correlated highly within a group but did not correlate with variables outside that group (Field, 2009). It was noted from the results that Line managers' participation in recruitment played a big role in ownership of departmental activities as well as was the benefits of teambuilding contribution to group cohesion. From the observation, it was clear that HRP improves recession was picked since it had the highest rating with 0.737 as compared with the rest which were all below it (Table 4).

\subsection{Modeling and Analysis}

Estimation of parameters and modeling of 5 items and presented on a Likert scale of high, moderate and low and was tabulated as indicated in Table 4.

Table 4. The SHRP estimation of parameters and modeling

\begin{tabular}{llll}
\hline & & N & Marginal Percentage \\
\hline Firm performance & High & 27 & 8.9 \\
& Moderate & 117 & 38.5 \\
No of Employees & Low & 160 & 52.6 \\
& Less than 499 & 114 & 37.5 \\
& 500 to 599 & 83 & 27.3 \\
& 1000 to 1999 & 37 & 12.2 \\
& 2000 to 2999 & 42 & 13.8 \\
HRP importance-recession & 3000 and above & 28 & 9.2 \\
HR Demand forecast & No & 123 & 40.5 \\
& Yes & 181 & 59.5 \\
& Trend & 111 & 36.5 \\
HRP alignment & Managerial & 157 & 51.6 \\
& Delphi & 13 & 4.3 \\
& None & 23 & 7.6 \\
& 1 & 36 & 11.8 \\
Total & 2 & 90 & 29.6 \\
& 3 & 102 & 33.6 \\
& 4 & 72 & 23.7 \\
& 5 & 4 & 1.3 \\
& & 305 & 100.0 \\
\hline
\end{tabular}


Table 4 shows estimation of parameters and modeling extraction. The estimation of parameters and modeling extraction system had five items on Likert scale and were confirmed valid. HRP importance during recession had the highest with $N$ equal to 181 (59\%) while HRP alignment had the lowest $N$ equal to 4 equivalent to 1.3. Based on the research outcomes, most (59\%) of the respondents believed HRP was important during recession. HRP importance during recession had the highest with $N$ equal to 181 representing $59 \%$ while HRP alignment had the lowest $N$ equal to 4 equivalent to 1.3 .

From the results of the study, the $\mathrm{HO}_{1}$ : Strategic human resource planning had no significant influence agricultural research organizations' performance in Kenya was not accepted since based on the research outcomes, majority (59\%) of the respondents believed HRP was important during recession. Hence, strategic human resource planning had a significance influence in agricultural research organizations' performance in Kenya.

\subsection{Recommendations}

Based on the study, the researcher recommends that KALRO and research institutions in entire, adopt strategic human resource planning in human resources planning. The empirical evidence from this study indicate that human resource planning had significant effect on organisations' performance of agricultural research organisations. The results of this study thus provide a valuable reference for managers of agricultural research institutions in Kenya in terms of what could enable them achieve competiveness and improve their performance.

\section{Conclusion}

The study concluded that strategic human resource planning had a significant factor in determining institutional performance of agricultural research in Kenya. The study recommends that strategic human resource planning be adopted by agricultural research institutes in Kenya since it had a significant factor in determining institutional performance. The empirical outcome from this study indicated that strategic human resource planning had a significant effect on institutional performance of agricultural research in Kenya. The results of this study thus provided a valuable reference for managers of agriculture in Kenya in terms of what could enable them achieve competitiveness and improved firm performance.

\section{Acknowledgement}

The authors are grateful to all employees of the Kenya Agricultural and Livestock Research Organisation KALRO that contributed in various ways. Dr. Jane Omwenga, Dr. Daniel Mutisya and Mr. Moses Owana technically analyzed the data. Dr. Noah Wawire, the KALRO Director of Agricultural Mechanization Research Institute and Dr. Elijah Gichuru of KALRO's Coffee Research Institute critiqued the paper. John Ayemba and Francis Ndegwa edited the paper for production. The Director General KALRO allowed the senior author to carry out the research as part of a PhD thesis at Jomo Kenyatta University of Agriculture and Technology.

\section{References}

Arasa, R., \& K'Obonyo, P. (2012). The relationship between strategic planning and firm Performance. International Journal of Humanities and Social Science Centre for Promoting Ideas, 2(22), 201-213.

Babbie, E., \& Mouton, J. (2010). The Practice of Social Research (10th ed.). Cape Town, Republic of South Africa: Oxford University Press Southern Africa.

Bass, B. M. (1985). Leadership and performance beyond expectations. New York: Free Press.

Best, O., \& James, W. (1993). Fundamentals of social research methods: An African perspective (3rd ed.). Lansdown: Juta Education.

Burns, J. M. (1978). Leadership. New York: Harper \& Row.

Byham, W. C., Smith, A. B., \& Paese, M. J. (2002). Grow your own leaders: How to identify, develop and retain leadership talent. New York, London: Prentice Hall.

Field, A. (2009). Discovering Statistics Using SPSS (3rd ed.). London: Sage Publications Ltd.

Fubara, B. (1986). Corporate Planning in Nigeria. Long Range Planning, 19(2), 125-132. https://doi.org/10.1016/0024-6301(86)90229-3

Kenneth, L. (2006). Strategy content and organizational performance: An empirical analysis. American Society for Public Administration Journal, 66(1), 1-154.

Mugenda, O. M., \& Mugenda, A. G. (2003). Research methods: Quantitative and qualitative Approaches. Nairobi: African Centre for Technology Studies. 
Mugenda, O. M., \& Mugenda, A. G. (1999). Research methods: Quantitative and qualitative Approaches. Nairobi: Acts Press.

Orodho, A. J. (2003). Essentials of Educational and Social Science Research Methods. Nairobi: Mazola Publishers.

Orodho, J. A. (2005). Elements of Education and Social Science Research Methods. Maseno: Kanezja Publishers.

Purvanova, R. K., Bono, J. E., \& Dzieweczynski, J. (2006). Transformational leadership, job characteristics, and organizational citizenship performance. Human Performance, 19(1), 1-22. https://doi.org/10.1207/s15327043hup1901_1

Republic of Kenya. (2007). Kenya Vision 2030: A Globally Competitive and Prosperous Kenya. Nairobi: Government Printer.

Yamane, T. (1967). Statistics, an Introductory Analysis (2nd ed.). New York: Harper and Row.

\section{Copyrights}

Copyright for this article is retained by the author, with first publication rights granted to the journal.

This is an open-access article distributed under the terms and conditions of the Creative Commons Attribution license (http://creativecommons.org/licenses/by/4.0/). 